\title{
Epidemiological review of childhood cancers in central Sudan
}

\begin{tabular}{|c|c|}
\hline \multicolumn{2}{|c|}{ 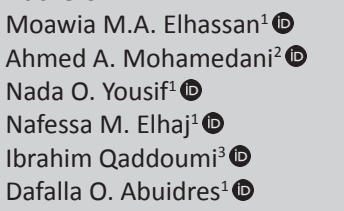 } \\
\hline \multicolumn{2}{|c|}{$\begin{array}{l}\text { Affiliations: } \\
{ }^{1} \text { Department of Clinical } \\
\text { Oncology, National Cancer } \\
\text { Institute, University of } \\
\text { Gezira, Sudan }\end{array}$} \\
\hline \multicolumn{2}{|c|}{$\begin{array}{l}\text { 2Department of Pathology, } \\
\text { University of Gezira, Sudan }\end{array}$} \\
\hline \multicolumn{2}{|c|}{$\begin{array}{l}{ }^{3} \text { Department of Global } \\
\text { Pediatric Medicine, St. Jude } \\
\text { Children's Research Hospital, } \\
\text { United States }\end{array}$} \\
\hline \multicolumn{2}{|c|}{$\begin{array}{l}\text { Corresponding author: } \\
\text { Moawia Elhassan, } \\
\text { moawia2@gmail.com }\end{array}$} \\
\hline \multicolumn{2}{|c|}{$\begin{array}{l}\text { Dates: } \\
\text { Received: } 27 \text { Jan. } 2018 \\
\text { Accepted: } 05 \text { Mar. } 2018 \\
\text { Published: } 03 \text { Apr. } 2018\end{array}$} \\
\hline \multicolumn{2}{|c|}{$\begin{array}{l}\text { How to cite this article: } \\
\text { Elhassan MMA, Mohamedani } \\
\text { AA, Yousif NO, Elhaj NM, } \\
\text { Qaddoumi I, Abuidres DO. } \\
\text { Epidemiological review of } \\
\text { childhood cancers in central } \\
\text { Sudan. S. Afr. j. oncol. } \\
\text { 2018;2(0), a37. https://doi. } \\
\text { org/10.4102/sajo.v2i0.37 }\end{array}$} \\
\hline \multicolumn{2}{|c|}{$\begin{array}{l}\text { Copyright: } \\
\text { (C) 2018. The Authors } \\
\text { Licensee: AOSIS. This } \\
\text { is licensed under the } \\
\text { Creative Commons } \\
\text { Attribution License. }\end{array}$} \\
\hline \multicolumn{2}{|l|}{ Read online: } \\
\hline 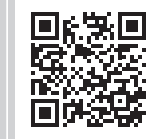 & $\begin{array}{l}\text { Scan this QR } \\
\text { code with your } \\
\text { smart phone or } \\
\text { mobile device } \\
\text { to read online. }\end{array}$ \\
\hline
\end{tabular}

Background: Epidemiological studies of paediatric cancer incidence in Sudan are rare.

Objectives: The aim of this study was to provide baseline information about the epidemiology of childhood cancers in patients treated at the National Cancer Institute (NCI) in Wad Medani, Sudan.

Methods: We performed a retrospective health facility-based study of cancer incidence and patient characteristics of children who were treated at the NCI from January 1999 to December 2015. The changing patterns of cancers incidence during the study period were also recorded.

Results: Of 15387 new patients with cancer who were registered at the NCI during the study period, $1159(7.5 \%)$ were children (younger than 15 years). The mean age of the paediatric patients was 7 years, with standard deviation of 5. Most of the patients (36\%) were 10 to 15 years old, 33\% were 0 to 4 years old and 31\% were 5 to 10 years old. Among the study population, $60 \%$ were males and $40 \%$ were females. Approximately $76 \%$ of children lived in rural areas in Sudan. Leukaemias (29\%) and lymphomas (26\%) comprised 55\% of all paediatric cancers. Central nervous system (CNS) tumours constituted $6 \%$ of all paediatric tumours, whereas non-CNS embryonal tumours (i.e. nephroblastoma, neuroblastoma, hepatoblastoma and retinoblastoma) accounted for $20 \%$. The average number of cases per year increased from 42 in 1999-2005 to 75 in 2006-2010 and 106 in 2011-2015.

Conclusion: The number of patients seeking treatment for childhood cancers has increased every year in central Sudan. Leukaemias and lymphomas constitute more than half of these cancers. A population-based cancer registry is needed to determine the true incidence of childhood cancers in Sudan.

\section{Introduction}

Childhood cancers are entities distinct from those occurring in adults. They are relatively rare, comprising less than $1 \%$ of malignant diseases. ${ }^{1}$ Marked differences in the incidence rates of childhood cancers are apparent in developed and developing countries. ${ }^{2,3}$ Of the estimated 250000 children in whom cancer is diagnosed every year, approximately 200000 live in countries with limited resources. ${ }^{4}$ In Africa, approximately 50000 new cases of childhood cancer are diagnosed every year. ${ }^{5}$

The frequencies at which different types of cancers occur also differ between high-income countries (HICs) and low- and middle-income countries (LMICs). Indeed, income-based variations have been observed even within the same country. The most common malignant neoplasms among children in developed countries are leukaemia and central nervous system (CNS) tumours. ${ }^{2}$ In Africa, CNS tumours are largely outnumbered by leukaemias and lymphomas. ${ }^{6,7}$ Geographic variations in the incidence rates at which different types of childhood cancers occur may suggest that genetic or environmental factors influence disease susceptibility. ${ }^{8}$ In many LMICs, the low incidence of some childhood tumours (especially brain tumours) is generally the consequence of failing to diagnose.

In HICs, more than $80 \%$ of children with malignant neoplasms are cured. However, most children with cancer live in LMICs, where the cure rate is much lower. ${ }^{9}$ Malnutrition and infectious disease, such as malaria, HIV and tuberculosis, remain the most important paediatric health problems in Africa. Consequently, childhood cancers remain a low priority on the health agendas of many African governments. Therefore, a basic epidemiological understanding of malignant diseases in children is urgently needed for optimal channelling of scarce health care resources in limited resource settings. Reports of the incidence of childhood cancers are limited in sub-Saharan Africa, 
and most of this information relies on hospital-based statistics. The South Africa Children Tumour Registry (SACTR) is the only paediatric cancer registry in Africa. ${ }^{10}$ The most extensive data on the incidence of childhood cancers in sub-Saharan Africa have been published recently. The data reported were extracted from six population-based cancer registries, which, as members of the African Cancer Registry Network, have been evaluated as achieving a reasonable degree of population coverage. ${ }^{11}$

In Sudan, where $40 \%$ of the population is under the age of 15 years, the true incidence of childhood cancers is unknown because of the lack of a national cancer registry. Reports of the occurrence of childhood cancers in Sudan are limited. In the absence of national cancer registries, hospital registries are the only source of information for assessing disease patterns. ${ }^{12,13}$ Here, we provide baseline information about the epidemiology of childhood cancers in central Sudan by reviewing hospital records of patients who were treated at the National Cancer Institute (NCI), the only cancer treating institution in central Sudan, from January 1999 to December 2015. Our findings may be generally representative of childhood cancers within the paediatric population of central Sudan.

\section{Methods \\ Setting}

The NCI, located in the central Sudanese state of Gezira, was established in 1989 in the Gezira capital Wad Medani. The NCI began treating patients with cancer in 1999. Today, the NCI serves approximately 4 million inhabitants of Gezira and additional patients from nearby states, such as Sennar, Gadarif, Blue Nile and Kassala. These states are connected to Wad Medani by a highway that connects these states to Khartoum, the capital of Sudan. The NCI is the only cancer treatment facility in the entire region; thus, the hospital registry functions similarly to a population-based registry. The cancer treatment modalities available at the NCI include radiotherapy, chemotherapy and palliative care. A complete clinical workup (e.g. ultrasound, X-rays, blood tests, bone marrow examination, tumour marker analysis and nuclear imaging) is available at NCI. In the region, there is one Computed tomography (CT) in the government hospital and one magnetic resonance imaging (MRI) scanner available in private hospitals. Histopathologic and cytopathologic studies are provided by the University of Gezira Medical Laboratory. Surgical operations were performed at Gezira National Center for Pediatric Surgery and Gezira Center for Neurosurgery, both of which are located in Wad Medani city.

\section{Study design}

We performed a retrospective health facility-based study to characterise the incidence of children with cancers who were treated at the NCI from January 1999 (i.e. the starting date of cancer treatment at the NCI) to December 2015. We analysed data obtained from patient case folders, pathology records and radiology reports. All records were retrieved from the NCI Records Department. We investigated each case for age at diagnosis, sex, place of residence, tumour sites and morphologic or histopathologic tumour information. Cancers were classified according to the International Classification of Childhood Cancer as set forth by the World Health Organization. ${ }^{2,14}$

\section{Statistical analysis}

Retrieved data were recorded in precoded protocol forms specifically designed for the study and then entered into a study database. The data were analysed with the Statistical Package for the Social Sciences (SPSS) version 20 statistical package. We present statistical data as frequency and percentage for a categorical variable or as both mean \pm standard deviation (s.d.) and median (range) for a continuous variable.

\section{Ethical considerations}

Ethical approval for this retrospective study was obtained from the NCI's ethical committee. Because of the retrospective nature of the study, the ethical committee waived the requirement of informed consent.

\section{Results}

Of 15387 new patients with cancer registered at the NCI from January 1999 to December 2015, 1159 (7.5\%) were children (younger than 15 years). Nearly all paediatric cancers (1134; 98\%) were diagnosed according to their histopathology, although 25 were diagnosed (all brainstem tumours) on the basis of clinical evaluation and imaging. The demographic data of the paediatric cancer population revealed that the median age at diagnosis was 6 years (range, 1-15 years). Cancers were categorised according to patient age groups as follows: 0 to 4 years, 5 to 9 years and 10 to 15 years. The distribution of children with cancer according to age group indicated that most (36\%) corresponded with the 10- to 15-year age group, followed by the 0 - to 4 -year (33\%) and 5- to 10-year (31\%) age groups. Of all children, $60 \%$ were boys and $40 \%$ were girls, with a male-to-female ratio of 1.5:1.0. Approximately $76 \%$ of the children lived in rural areas.

Leukaemias were the highest frequency cancer type (29\%) followed closely by lymphomas (26\%) (Table 1). Non-CNS embryonal tumours (i.e. nephroblastoma, neuroblastoma, hepatoblastoma and retinoblastoma) occurred in 209 cases (19\%). Among them, nephroblastoma was more frequent than neuroblastoma, retinoblastoma and hepatoblastoma. CNS tumours were the fifth $(6 \%)$ most commonly found tumours in children who were treated at the NCI during the study period. The nasopharynx region accounted for $52 \%$ of all carcinomas diagnosis (29/55).

Most of these cancers occurred more commonly in boys than in girls, whereas nephroblastomas, soft tissue sarcomas, germ cell tumours and malignant bone tumours predominately occurred in female children (Table 1). 
TABLE 1: Distribution of childhood cancers according to patient age, sex and relative frequency $(n=1159)$.

\begin{tabular}{|c|c|c|c|c|c|c|}
\hline \multirow[t]{2}{*}{ Cancer type } & \multicolumn{4}{|c|}{ Number of patients } & \multirow{2}{*}{$\begin{array}{l}\text { Male-to-female } \\
\text { ratio }\end{array}$} & \multirow{2}{*}{$\begin{array}{c}\text { Relative } \\
\text { frequency (\%) }\end{array}$} \\
\hline & $0-4$ years & $5-9$ years & $10-15$ years & Total & & \\
\hline Leukaemias & 94 & 113 & 133 & 340 & 1.6 & 29.3 \\
\hline Lymphomas & 68 & 117 & 116 & 301 & 2.4 & 26.0 \\
\hline Central nervous system tumours & 9 & 29 & 33 & 71 & 1.6 & 6.1 \\
\hline Neuroblastoma & 34 & 12 & 1 & 47 & 1.2 & 4.1 \\
\hline Retinoblastoma & 46 & 10 & 0 & 56 & 1.2 & 4.8 \\
\hline Nephroblastoma & 71 & 25 & 10 & 106 & 0.9 & 9.2 \\
\hline Liver tumours & 7 & 2 & 4 & 13 & 1.2 & 1.1 \\
\hline Bone tumours & 1 & 5 & 31 & 37 & 0.8 & 3.2 \\
\hline Soft tissue sarcomas & 22 & 26 & 30 & 78 & 0.8 & 6.7 \\
\hline Germ cell tumours & 8 & 6 & 14 & 28 & 0.3 & 2.4 \\
\hline Carcinomas & 4 & 10 & 41 & 55 & 1.6 & 4.8 \\
\hline Other tumours & 12 & 9 & 6 & 27 & 2.9 & 2.3 \\
\hline Total & 376 & 364 & 419 & 1,159 & 1.5 & 100 \\
\hline
\end{tabular}

TABLE 2: Distribution of childhood cancers according to patient age group and $\operatorname{sex}(n=1159)$.

\begin{tabular}{lccccc}
\hline Age group & \multicolumn{5}{c}{ Number of patients } \\
\cline { 2 - 6 } & Boys & $\mathbf{\%}$ & Girls & $\mathbf{\%}$ & Total \\
\hline $0-4$ & 208 & 55 & 168 & 45 & 376 \\
$5-9$ & 230 & 63 & 134 & 37 & 364 \\
$10-15$ & 253 & 60 & 166 & 40 & 419 \\
\hline Total & $\mathbf{6 9 1}$ & $\mathbf{6 0}$ & $\mathbf{4 6 8}$ & $\mathbf{4 0}$ & $\mathbf{1 1 5 9}$ \\
\hline
\end{tabular}

When we analysed cancer type according to patient age groups, we found that leukaemias were the most frequent cancer type in the 0 - to 4-year and 10- to 15-year age groups, whereas lymphomas were the most frequent in the 5- to 9-year age group (Table 1). We observed that lymphomas, leukaemias, CNS tumours and malignant bone tumours most commonly occurred in children older than 5 years, whereas retinoblastoma, nephroblastoma and neuroblastoma occurred most commonly in children younger than 5 years. No cases of retinoblastoma were reported in the 10- to 15 -year age group. Approximately $84 \%$ of malignant bone tumours occurred in the 10 - to $15-$ year age group. The male predominance was found in all age groups (Table 2 ).

To determine changes in the incidence and relative proportion of childhood cancers at the NCI over time, we categorised the number of childhood cancer cases according to three specific time periods: 1999-2005, 2006-2010 and 2011-2015. The total number of childhood cancer cases increased for each subsequent time period (Table 3). The average number of cases per year increased from 42 in 1999-2005 to 75 in 20062010 and 106 in 2011-2015. For the 1999-2005 period, lymphomas were the most frequent diagnoses. However, the rate of leukaemias increased and became the most common cancer type for the 2006-2010 and 2011-2015 periods. We also observed considerable changes in the frequency of CNS tumours and neuroblastomas over time.

The median age of children with cancer who lived in rural areas was 6 years and for those who lived in urban areas it was 5 years. Children from rural areas had a male-to-female ratio of 1.5 , whereas those from urban areas had a male-tofemale ratio of 1.3 .

\section{Discussion}

Childhood cancer is rare everywhere in the world, with an age-standardised annual incidence generally between 94 and 142 per million children aged 0 to 14 years. Cancer incidence in children is higher in more developed countries (113-142 per million) than in less developed countries (85 per million). ${ }^{15}$ Although the source of variability between populations for some specific childhood cancer types is largely unknown, it is most likely related to exposure to risk factors. ${ }^{15}$ Furthermore, underreporting may contribute to a low incidence of childhood cancers in limited resource settings. ${ }^{16}$ In Africa, only $11 \%$ of the population is included in a cancer-based registry. ${ }^{17}$

In Sudan, the main sources of data on childhood cancers are found in hospital-based case series. ${ }^{12,13,18,19}$ Among all patients admitted to the NCI for treatment during the study period, children with cancers constituted 7.5\%. This finding is similar to those of a previous study in Sudan, in which childhood cancers constituted approximately $7 \%$ of all cancer cases registered in the state of Khartoum from 2009 to $2010 .{ }^{20}$ This is also comparable with reports from other sub-Saharan African countries, where the proportion of childhood cancer out of all cancers varies between $1.4 \%$ and $10 \% .{ }^{21}$ But the proportion of childhood cancers in this study seems to be high compared to that of HIC. Possible reasons for this difference could be that our data are from a hospital and so are not a true representation of the cancer burden. Moreover, the higher proportion of children in Sudan, as $40 \%$ of population is under the age of 15 years (Figure 1), could be a possible explanation of the high number of childhood cancers.

An interesting finding of our study is the increasing number of paediatric patients with cancer who were treated at the NCI during the study period. This is also similar with reports from other countries in Africa. ${ }^{22,23,24}$ This finding most likely reflects increased public awareness, increased awareness by general health care providers of the NCI and improved referral patterns as other centres in the region became aware of our hospital, which all contribute to the overall improved health care-seeking behaviour of the community. This suggests that when parents are provided with the opportunity 
for the care they seek for their children, they will travel long distances to receive treatment from what they perceive as a high-quality cancer hospital.

The preponderance of boys in this study was similar to that observed in general trends in Africa and Asia ${ }^{11,23,25,26,27,28,29}$ but different from that observed in developed countries, where the male-to-female ratio is 1:1. This sex bias most likely reflects a cultural tradition of placing a higher value on boys than on girls, rather than actual increased incidence of cancer in boys.

The frequencies at which different types of cancers occur differ between HIC and LMICs. Comparative relative frequencies data from other LMIC countries and HIC are shown in Table $4 . .^{30,31}$

We found leukaemias to be the most frequent paediatric cancer, followed by lymphoma and Wilms tumour. This

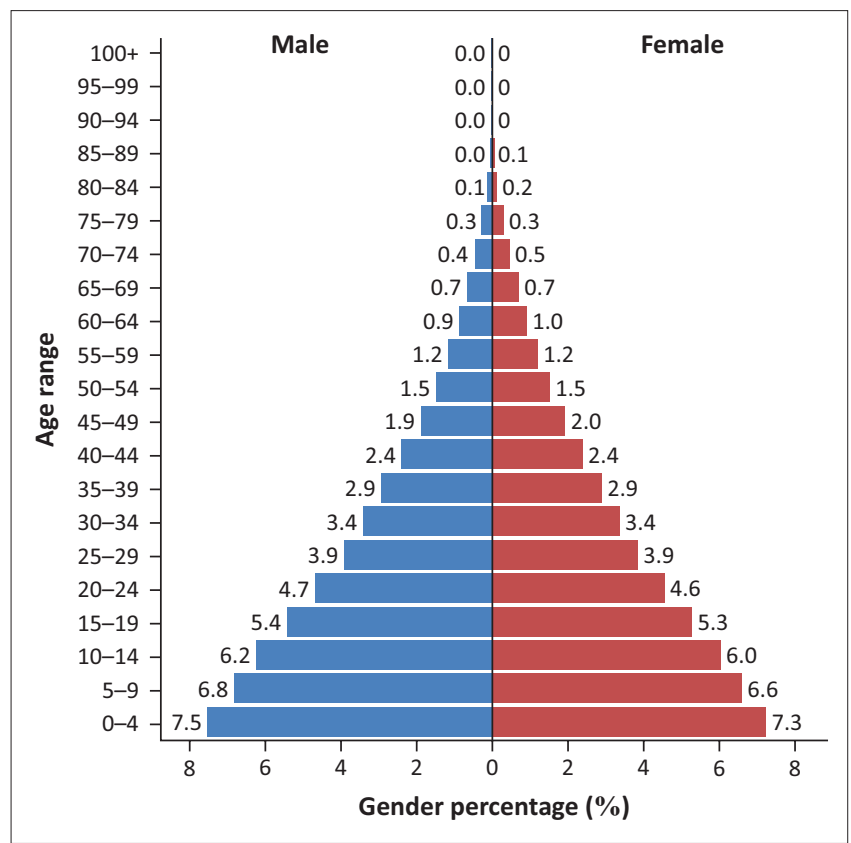

Source: https://www.populationpyramid.net/sudan/2015/

Population $=40234882$.

FIGURE 1: Population pyramid of Sudan, 2015 finding is similar to that reported in a previous study conducted in Khartoum. ${ }^{20}$ Similar findings have also been reported for countries in northern Africa, South Africa and Namibia. ${ }^{10,28,32,33}$ This is in contrast to many LMICs, where leukaemias are much less frequent than lymphomas. . $^{81,22,34}$ We found that most children with leukaemias were boys, which is also similar to that reported in other studies. ${ }^{23,35}$ Most of the children in our analysis resided in rural regions of Sudan, where tertiary medical care is lacking. It is plausible that some children with leukaemia may have died before registration or diagnosis. Interestingly, during the first period (1999-2005), lymphomas were the most frequently occurring cancers. In contrast, leukaemias were the most common cancer types in later periods (2006-2010 and 2011-2015). This could represent either a true increase in the incidence of leukaemias or an improvement in clinical and laboratory diagnoses or better registrations in the Cancer Registries.

In HICs, lymphomas are the third most common childhood cancer, following leukaemias and CNS tumours. We found that lymphomas were the second most frequent cancer type in children treated at the NCI. Similar findings have been reported for northern African countries, South Africa and India..$^{24,28,36}$ This is in contrast to previous studies from other African countries that reported lymphomas as the most common tumours affecting the paediatric population. . $^{11,22,34}$ We found that the majority of children with lymphomas were older than 5 years, which is similar to the findings of a recent report from Yemen. ${ }^{29}$

In $\mathrm{HICs}, \mathrm{CNS}$ tumours are the second most diagnosed cancers and represent $20 \%$ to $27 \%$ of all paediatric cancers. ${ }^{37}$ The incidence of CNS tumours in our study was lower than that reported in HICs. The incidence of CNS tumours is reduced in LMICs, which may reflect ethnic variation or limited neurosurgical resources or attenuated availability of advanced imaging equipment, such as CT and MRI scanners. ${ }^{8,19}$ In the current study, the steep increase in the relative frequency of CNS tumours reported in the second and third periods (20062010 and 2011-2015) compared to the first period (1999-2005) is likely because of the introduction of CT scan, MRI and neurosurgical services in central Sudan.

TABLE 3: The number and relative frequencies of childhood cancers by period of diagnosis $(n=1159)$.

\begin{tabular}{|c|c|c|c|c|}
\hline \multirow[t]{2}{*}{ Cancer type } & \multicolumn{3}{|c|}{ Period of diagnosis } & \multirow[t]{2}{*}{ Total $N(\%)$} \\
\hline & $\begin{array}{c}1999-2005 \\
n(\%)\end{array}$ & $\begin{array}{c}2006-2010 \\
n(\%)\end{array}$ & $\begin{array}{c}2011-2015 \\
n(\%)\end{array}$ & \\
\hline Leukaemias & $63(24.9)$ & $97(25.9)$ & $180(33.9)$ & $340(29.3)$ \\
\hline Lymphomas & $95(37.5)$ & $96(25.6)$ & $110(20.7)$ & $301(26.0)$ \\
\hline Central nervous system tumours & $5(2.0)$ & $30(8.0)$ & $36(6.8)$ & $71(6.1)$ \\
\hline Neuroblastoma & $0(0.0)$ & $23(6.1)$ & $24(4.5)$ & $47(4.1)$ \\
\hline Retinoblastoma & $7(2.8)$ & $19(5.1)$ & $30(5.6)$ & $56(4.8)$ \\
\hline Nephroblastoma & $32(12.6)$ & $37(9.9)$ & $37(7.0)$ & $106(9.2)$ \\
\hline Liver tumours & $3(1.2)$ & $4(1.1)$ & $6(1.1)$ & $13(1.1)$ \\
\hline Bone tumours & $11(4.3)$ & $12(3.2)$ & $14(2.6)$ & $37(3.2)$ \\
\hline Soft tissue sarcomas & $16(6.3)$ & $21(5.6)$ & $41(7.7)$ & $78(6.7)$ \\
\hline Germ cell tumours & $7(2.8)$ & $8(2.1)$ & $13(2.4)$ & $28(2.4)$ \\
\hline Carcinomas & $11(4.3)$ & $20(5.3)$ & $24(4.5)$ & $55(4.8)$ \\
\hline Other tumours & $3(1.2)$ & $8(2.1)$ & $16(3.0)$ & $27(2.3)$ \\
\hline
\end{tabular}


TABLE 4: Comparative relative frequencies data from other low- and middle-income countries countries ${ }^{10,34}$ and high-income countries. ${ }^{30,31}$

\begin{tabular}{|c|c|c|c|c|c|}
\hline \multirow[t]{2}{*}{ Cancer type } & \multicolumn{5}{|c|}{ Relative frequencies (\%) } \\
\hline & United States of America & England & South Africa & Tanzania & Current study \\
\hline Leukaemias & 30.2 & 29.9 & 25.4 & 15.0 & 29.3 \\
\hline Lymphomas & 10.9 & 10.7 & 13.5 & 35.0 & 26.0 \\
\hline $\begin{array}{l}\text { Central nervous system } \\
\text { tumours }\end{array}$ & 21.0 & 24.9 & 13.4 & 0.0 & 6.1 \\
\hline Neuroblastoma & 8.2 & 5.9 & 5.4 & 1.0 & 4.1 \\
\hline Retinoblastoma & 3.0 & 2.6 & 7.1 & 11.0 & 4.8 \\
\hline Hepatic tumours & 1.3 & 1.3 & 2.1 & 5.0 & 1.1 \\
\hline Malignant bone tumour & 4.7 & 4.3 & 4.5 & 3.0 & 3.2 \\
\hline Soft tissue sarcomas & 7.0 & 6.6 & 9.5 & 9.0 & 6.7 \\
\hline Germ cells tumour & 3.3 & 3.6 & 3.3 & 2.0 & 2.4 \\
\hline Others tumours & 4.1 & 4.6 & 3.5 & 5.0 & 7.1 \\
\hline
\end{tabular}

We found that nephroblastoma was the third most frequent cancer affecting children at the NCI. This finding is slightly higher than the findings observed by Jabeen et al., in which nephroblastoma accounted for $6.8 \%$ of childhood cancers. ${ }^{38}$ According to the SACTR, nephroblastomas are the fourth most frequent childhood cancer in South Africa. ${ }^{10}$ The frequency and demographics of nephroblastoma in central Sudan are in accordance with those reported worldwide, in which nephroblastomas occur primarily in children less than 5 years and with equal frequency in boys and girls.

Retinoblastoma is the most common intraocular cancer in children. In most HICs, retinoblastoma represents $2.4 \%$ to $4 \%$ of all paediatric cancers. ${ }^{39,40}$ This is similar to our findings but low when compared with the frequency of retinoblastoma reported in some LMICs. ${ }^{34,41}$ The data from Africa suggest that, in many of the populations of sub-Saharan Africa, rates are rather higher than in HICs. ${ }^{11}$ We found that most retinoblastomas occurred in children younger than 5 years, which is similar to findings reported in other studies. .11,42,43 $^{-1}$ Although retinoblastoma is highly curable if diagnosed early, most children with retinoblastoma who are referred to the $\mathrm{NCI}$ are at an advanced stage. ${ }^{44}$

Malignant bone tumours comprise approximately 5\% of childhood neoplasms. ${ }^{45}$ We observed that the rate of bone cancers was lower than expected. The causes of reduced incidence of childhood bone cancers at the NCI are unknown. The incidence of bone cancer is similar across the sexes and rises steeply with age. ${ }^{45}$ Concordantly, we found that more than two-thirds of the bone cancer cases reported at the NCI occurred in children aged 10 to 14 years, but most cases occurred in girls.

In most developed countries, neuroblastoma accounts for $6 \%$ to $10 \%$ of all childhood cancers. However, the frequency of neuroblastoma was reduced in children treated at the NCI during the study period. Low frequencies of neuroblastoma have also been reported in other sub-Saharan African countries, the percentage was between $3 \%$ and $5 \%$ of all childhood cancers seen (except Madagascar, where the frequency was $7.5 \%){ }^{11}$ As expected, we found that most neuroblastoma cases occurred in children younger than 9 years, with the majority occurring in children younger than
5 years. We found that neuroblastoma predominantly affected female children. This is in contrast with other studies, which have identified the male sex as a risk factor for neuroblastoma. ${ }^{46,47}$

Childhood carcinomas are rare. Consequently, they occurred infrequently in children with cancer who were treated at the NCI. Most of these cases occurred in children older than 9 years and in boys, which is similar to findings reported from Yemen. ${ }^{29}$ Nasopharyngeal carcinoma, which is very rare worldwide, ${ }^{48}$ was the most incident carcinoma in children at the NCI.

Primary neoplasms of the liver constitute $0.5 \%$ to $2 \%$ of cases in children younger than 15 years ${ }^{49}$ At the NCI, we observed a similar frequency of liver cancers in children. Hepatitis B infection is considered as the most important factor associated with hepatocellular carcinoma in children. ${ }^{50}$ In Taiwan, Chiang et al. reported that the national hepatitis B vaccination programme that began in 1984 has been associated with over $70 \%$ reduction in the liver cancer rates among children and adolescents. ${ }^{51}$ In our study, hepatitis B probably does not play a major role as the majority of liver tumours were in those under 4 years of age where they are almost certainly going to be hepatoblastomas.

Because our study was limited to a single institution, we cannot make conclusions on the general status of childhood cancers for all of Sudan. However, the NCI is the only cancer referral oncology institute in central Sudan; therefore, data from the NCI are the best indicator of the disease burden within this region. Nevertheless, this study provides insight into the characteristics of childhood cancers in a limited resource setting and lays the foundation for improvements in cancer care in Sudan. The findings of this study also have the potential to trigger further research into the area of childhood cancers in Sudan.

\section{Conclusion}

This study provides baseline information about the epidemiology of childhood cancers in central Sudan by reviewing hospital records of patients who were treated at NCI. There was apparently rising incidence of childhood 
cancers associated with the growing influence of the specialised cancer centre in the region. Leukaemias and lymphomas constituted more than half of our study population. There was a low incidence of CNS tumours, which is a common finding in under-resourced settings. A population-based cancer registry is needed to determine the true incidence of childhood cancers in Sudan.

\section{Acknowledgements}

We thank Dr Nisha Badders from the Department of Scientific Editing at St. Jude Children's Research Hospital for editing the manuscript.

\section{Competing interests}

The authors declare that they have no financial or personal relationships that may have inappropriately influenced them in writing this article.

\section{Authors contributions}

M.M.A.E. was the project leader. M.M.A.E., A.A.M., N.O.Y., N.M.E., I.Q. and D.O.A. contributed to the design and implementation of the research, analysis of the results and writing of the manuscript.

\section{References}

1. Steliarova-Foucher E, Stiller C, Kaatsch P, et al. Geographical patterns and time trends of cancer incidence and survival among children and adolescents in Europe since the 1970s (the ACCIS project): An epidemiological study. Lancet. 2004; 364:2097-2105. https://doi.org/10.1016/S0140-6736(04)17550-8

2. Parkin DM, Kramarova $E$, Draper $\mathrm{Gl}$, et al. The international incidence of childhood cancer. Int J Cancer. 1988;42:511-520. https://doi.org/10.1002/ijc.2910420408

3. Miller RW. Epidemiologic evidence for genetic variability in the frequency of cancer: Ethnic differences. Basic Life Sci. 1988;43:65-70. https://doi.org/ 10.1007/978-1-4684-5460-4_7

4. Kellie SJ, Howard SC. Global child health priorities: What role for paediatric oncologists? Eur J Cancer. 2008;44:2388-2396. https://doi.org/10.1016/j. ejca.2008.07.022

5. Stefan DC, Harford J, Stones D, et al. Hope for African children with cancer: African Pediatric Oncology Group. Pediatr Blood Cancer. 2012;59:349. https://doi.org/ 10.1002/pbc.24069

6. Stiller CA. Epidemiology and genetics of childhood cancer. Oncogene. 2004;23:6429-6444. https://doi.org/10.1038/sj.onc.1207717

7. Stiller CA, Parkin DM. Geographic and ethnic variations in the incidence of childhood cancer. Br Med Bull. 1996;52:682-703. https://doi.org/10.1093/ oxfordjournals.bmb.a011577

8. Howard SC, Metzger ML, Wilimas JA, et al. Childhood cancer epidemiology in low-income countries. Cancer. 2008;112:461-472. https://doi.org/10.1002/ cncr.23205

9. Brown BJ, Bamgboye EA, Sodeinde O. Causes of death in childhood cancer at the Department of Paediatrics, University College Hospital, Ibadan. Af J Med Sci. 2008;37:7-13.

10. Stefan DC, Stones DK. The South African Paediatric Tumour Registry -25 years of activity. S Afr Med J. 2012;102:605-606. https://doi.org/10.7196/SAMJ.5719

11. Stefan C, Bray F, Ferlay J, Parkin DM, Liu B. Cancer of Childhood in sub-Saharan Africa. ecancer. 2017;11:755. https://doi.org/10.3332/ecancer.2017.755

12. Haroun HM, Mahfouz MS, Elhaj AM. Patterns of childhood cancer in children admitted to the Institute of Nuclear Medicine, Molecular Biology and Oncology (INMO), Wad Medani, Gezira State. J Family Community Med. 2006;13:71-74.

13. Abuidris DO, Ahmed ME, Elgaili EM, Arora RS. Childhood cancer in Sudan: 19992007. Trop Doct. 2008;38:208-210. https://doi.org/10.1258/td.2008.070408

14. Kramarova E, Stiller CA. The international classification of childhood cancer. Int Cancer.1996;68:759-765. https://doi.org/10.1002/(SICI)1097-0215(19961211)68: 6\%3C759::AID-IJC12\%3E3.0.CO;2-W

15. Magrath I, Steliarova-Foucher E, Epelman S, et al. Paediatric cancer in low-income and middle-income countries. Lancet Oncol. 2013;14:104-116. https://doi. org/10.1016/S1470-2045(13)70008-1
16. Hossain MS, Begum M, Mian MM, et al. Epidemiology of childhood and adolescent cancer in Bangladesh, 2001-2014. BMC Cancer. 2016:16:104 https://doi. org/10.1186/s12885-016-2161-0

17. Parkin DM. The evolution of the population-based cancer registry. Nature Rev Cancer. 2006;6:603-612. https://doi.org/10.1038/nrc1948

18. Elhassan MMA, Taha TO. Brainstem tumour in children in a limited resource setting: A single-institution experience. Sud JMS. 2016;11:183-190.

19. Elhassan MMA, Osman HHM, Parkes J. Posterior cranial fossa tumours in children at National Cancer Institute, Sudan: A single institution experience. Childs Nerv Syst. 2017;33:1303-1308. https://doi.org/10.1007/s00381-017-3414-1

20. Saeed IE, Weng HY, Mohamed KH, Mohammed SI. Cancer incidence in Khartoum Sudan: First results from the Cancer Registry, 2009-2010. Cancer Med. 2014;3:1075-1084. https://doi.org/10.1002/cam4.254

21. Stefan DC. Patterns of distribution of childhood cancer in Africa. J Trop Pediatr. 2015;61:165-173. https://doi.org/10.1093/tropej/fmv005

22. Yao JJ, Couitchere L, Atimere Y, et al. Childhood cancer in Cote d'Ivoire, 19952004: Challenges and hopes. S Afr Med J. 2012;103:113-115. https://doi.org/ 10.7196/SAMJ.6365

23. Yifru S, Muluye D. Childhood cancer in Gondar University Hospital, Northwest Ethiopia. BMC Res Notes. 2015;8:474. https://doi.org/10.1186/s13104-015 1440-1

24. Stefan DC. Epidemiology of childhood cancer and the SACCSG tumour registry Contin Med Edu. 2010;28:317-319.

25. Yared T, Etsegenet G. Pattern of childhood malignancies in a university referral hospital in Addis Ababa. Ethiop J Pediatrics Child Health. 2008;4:27-31.

26. Jamal S, Mamoon N, Mushtaq S, et al. Pattern of childhood malignancies: Study of 922 cases at Armed Forces Institute of Pathology (AFIP), Rawalpindi, Pakistan. Asian Pac J Cancer Prev. 2006;7:420-422.

27. Al-Tarawneh M, Khatib S, Arqub K. Cancer incidence in Jordan, 1996-2005. East Mediterr Health J. 2010;16:837-845.

28. Missaoui $\mathrm{N}$, Khouzemi M, Landolsi $\mathrm{H}$, et al. Childhood cancer frequency in the center of Tunisia. Asian Pac J Cancer Prev. 2011;12:537-542.

29. Jawass MA, Al-Ezzi JI, Bin Gouth HS, et al. Pattern of malignancies in children $<15$ years of age reported in Hadhramout Cancer Registry, Yemen between 2002 and 2014. Saudi Medical J. 2016;37:513-520. https://doi.org/10.15537/ smj.2016.5.14954

30. Linet MS, Ries LG, Smith MA, Tarone RE, Devesa SS. Cancer surveillance series: Recent trends in childhood cancer incidence and mortality in the United States. J Natl Cancer Inst. 1999;91:1051-1058. https://doi.org/10.1093/jnci/91. 12.1051

31. Childhood cancer registration in England: 2015 to 2016. London: National Cancer Registration and Analysis Service, Public Health England; 2016.

32. Hosny G, Elkaffas SM. Patterns in the incidence of pediatric cancer in Alexandria, Egypt, from 1972 to 2001. J Egypt Public Health Assoc. 2002;77:451-468.

33. Stefan DC, Baadjes B, Kruger M. Incidence of childhood cancer in Namibia: The need for registries in Africa. Pan Afr Med J. 2014;17:191. https://doi.org/10.11604/ pamj.2014.17.191.3830

34. Schroeder K, Saxton A, McDade J, et al. Pediatric cancer in Northern Tanzania: Evaluation of diagnosis, treatment, and outcomes. J Global Oncol. 2017;4:1-10. https://doi.org/10.1200/JGO.2016.009027

35. Makata AM, Toriyama K, Kamidigo NO, et al. The pattern of pediatric solid malignant tumors in western Kenya, east Africa, 1979-1994: An analysis based on histopathologic study. Am J Trop Med Hyg. 1996;54:343-347. https://doi.org/ 10.4269/ajtmh.1996.54.343

36. Bhalodia Jignasa N, Patel Mandakini M. Profile of pediatric malignancy: A three year study. Nat J Comm Med. 2011;2:24-27.

37. Ward E, DeSantis C, Robbins A, et al. Childhood and adolescent cancer statistics, 2014. CA Cancer J Clin. 2014;64:83-103. https://doi.org/10.3322/caac.21219

38. Jabeen $\mathrm{S}$, Haque $\mathrm{M}$, Islam $\mathrm{M}$, et al. Profile of paediatric malignancies: A five year study. J Dhaka Med Coll. 2010;19:33-38. https://doi.org/10.3329/jdmc.v19i1. 6249

39. Sang DN, Albert DM, Kuo PK. Retinoblastoma: Clinical observations and histopathological study. Int Ophthalmol Clin. 1982;22:73-102. https://doi. org/10.1097/00004397-198202230-00008

40. Parkin DM, Kramárová E, Draper GJ, et al. International incidence of childhood cancer. IARC Sci Pub. 1998;II:144.

41. Owoeye JF, Afolayan EA, Ademola-Popoola DS. Retinoblastoma - A clinicopathological study in Ilorin, Nigeria. Afr J Health Sci. 2006;13:117-123. https:// doi.org/10.4314/ajhs.v12i3.30805

42. Ba-Saddik IA. Childhood cancer in Aden, Yemen. Cancer Epidemiol. 2013; 37 803-806. https://doi.org/10.1016/j.canep.2013.10.001

43. Broaddus $E$, Topham A, Singh AD. Incidence of retinoblastoma in the USA: 19752004. Br J Ophthalmol. 2009;93:21-23. https://doi.org/10.1136/bjo.2008.138750

44. Ali AA, Elsheikh SM, Elhaj A, et al. Clinical presentation and outcome of retinoblastoma among children treated at the National Cancer Institute $(\mathrm{NCl})$ in Gezira, Sudan: A single institution experience. Ophthalmic Genet. 2011;32:122-125. https://doi.org/10.3109/13816810.2010.546822

45. Parkin DM, Stiller CA, Nectoux J. International variations in the incidence of childhood bone tumours. Int J Cancer. 1993;53:371-376. https://doi.org/10.1002/ ijc. 2910530305 
46. Cotterill SJ, Pearson AD, Pritchard J, et al. Clinical prognostic factors in 1277 patients with neuroblastoma: Results of the European Neuroblastoma Study
Group 'Survey' 1982-1992. Eur J Cancer. 2000;36:901-908. https://doi.org/ 10.1016/S0959-8049(00)00058-7

47. Tulla M, Berthold F, Graf N, et al. Incidence, trends, and survival of children with embryonal tumors. Pediatrics. 2015;136:623-632. https://doi.org/10.1542/ peds.2015-0224

48. Liu W, Tang Y, Gao L, et al. Nasopharyngeal carcinoma in children and adolescents - A single institution experience of 158 patients. Radiat Oncol. 2014;9:274 https://doi.org/10.1186/s13014-014-0274-7
49. Tsai HL, Liu CS, Chin TW, et al. Hepatoblastoma and hepatocellular carcinoma in children. J Chi Med Assoc. 2004;67:83-88.

50. Hsiao CC, Chuang JH, Tiao MM, et al. Patterns of hepatoblastoma and hepatocellular carcinoma in children after universal hepatitis B vaccination in Taiwan: A report from a single institution in southern Taiwan. J Pediatr Tematol Ancol. 2009:31:91-96. https://doi.org/10.1097/MPH.0b013e3181 8 b3784

51. Chiang CJ, Yang YW, You SL, et al. Thirty-year outcomes of the national hepatitis B immunization program in Taiwan JAMA. 2013;310(9):974-976. 